\title{
Myo-Inositol and Sorbitol Metabolism in Relation to Peripheral Nerve Function in Experimental Diabetes in the Rat: The Effect of Aldose Reductase Inhibition
}

\author{
K. R. W. Gillon ${ }^{1}$, J. N. Hawthorne' ${ }^{1}$ and D. R. Tomlinson ${ }^{2}$ \\ Departments of ${ }^{1}$ Biochemistry and ${ }^{2}$ Physiology and Pharmacology, University Hospital and Medical School, Nottingham, UK
}

\begin{abstract}
Summary. A possible relationship between increased sorbitol concentration and decreased myo-inositol concentration in peripheral nerves of diabetic rats has been examined. To this end, sorbinil, an aldose reductase inhibitor, was used either to prevent or reverse elevation of nerve sorbitol concentration in diabetic rats. Sorbinil treatment at $20 \mathrm{mg} \cdot \mathrm{kg}^{-1} \cdot$ day $^{-1}$ prevented elevation of nerve sorbitol levels in early diabetes and reduced sorbitol concentration from 2.38 to $0.51 \mu \mathrm{mol} / \mathrm{g}$ in rats diabetic for 10 weeks. This treatment reduced the increase in nerve fructose concentration and prevented the reduced myo-inositol concentration found in diabetic rat nerve (control 3.63, diabetic 2.40, diabetic/sorbinil, $3.56 \mu \mathrm{mol} / \mathrm{g}$ ). Sorbinil treatment did not prevent a significant slowing of motornerve conduction velocity at 10 weeks although treatment reduced the extent of slowing. Sorbinil treatment at $25 \mathrm{mg}$.
\end{abstract}

$\mathrm{kg}^{-1} \cdot$ day $^{-1}$ reduced elevated sorbitol and fructose concentrations in diabetic rat nerve and normalised myo-inositol concentration. Myo-Inositol treatment at $650 \mathrm{mg} \cdot \mathrm{kg}^{-1}$. day $^{-1}$ did not affect the elevated concentrations of sorbitol, fructose or glucose in peripheral nerves of diabetic rats, but it did restore reduced myo-inositol concentration. Both sorbinil and myo-inositol treatment partially reversed the slowing of motor-nerve conduction velocity in diabetic rats. These results are discussed in relation to the involvement of sorbitol and myo-inositol metabolism in the aetiology of diabetic neuropathy.

Key words: Myo-Inositol, sorbitol, motor nerve conduction velocity, aldose reductase, sorbinil.
Induction of experimental diabetes in the rat with alloxan or streptozotocin results in a well-characterized slowing of motor-nerve conduction velocity (MNCV) [1-5], mixed nerve conduction velocity [6] and a more recently demonstrated fall in sensory-nerve conduction velocity $[7,8]$. Structural alterations also appear to be present and take the form of axonal degeneration [9-11], with possibly demyelination/remyelination [11] and myelin reduction [12].

It is now considered that early metabolic abnormalities, rather than vascular changes, cause diabetic neuropathy [13]. Peripheral nerve glucose concentration is markedly elevated following induction of diabetes and this leads to increased sorbitol levels $[14,15]$ via the action of the enzyme aldose reductase [15]. This increase has led to the sorbitol theory of diabetic neuropathy. Since sorbitol is not freely diffusible, its accumulation in compartments within peripheral nerve may lead to osmotic changes, cell damage and hence slowed nerve conduction velocity [15]. Accompanying these changes, although not necessarily connected with them, is a reduction in peripheral nerve free myo-inositol concen- tration $[2,14]$ with resultant altered metabolism of the phosphoinositides $[8,16-18]$ which are thought to be involved in conduction of the nerve impulse [19].

To date, no study has attempted to correlate increased polyol pathway activity in peripheral nerve during experimental diabetes with reduced free myo-inositol concentration. In recent years, increasing interest has been focussed on the potential to reduce nerve sorbitol concentrations of a group of compounds which inhibit aldose reductase. This study describes the use of such a compound, CP-45,634 (+)6-fluoro-spiro[chroman-4,4'-imidazolidine]-2',5'-dione) ('sorbinil', Pfizer, Sandwich, Kent, UK) to reduce elevated sorbitol concentrations in streptozotocin-diabetic rat nerve. The consequent changes in myo-inositol concentration are described. In view of the implications this may have for nerve function in diabetes, serial motor-nerve conduction velocities were determined also in the same animals treated with sorbinil. In addition, a comparative study of the effect of either sorbinil or myo-inositol treatment on $\mathrm{MNCV}$ is described, since dietary myo-inositol supplementation has previously been shown to improve 
MNCV in acutely diabetic rats [2]. A short preliminary account of some of the present work has been published [20].

\section{Materials and Methods}

Male Wistar rats weighing 270-320 g were from the Nottingham University Joint Animal Breeding Unit, Sutton Bonington, Leicestershire, UK and were fed standard laboratory diet ad libitum (Diet 41B, Heygate \& Sons, Northampton, UK; myo-inositol content $0.022 \%$ ).

Induction of diabetes was achieved by a single IP injection of streptozotocin (Sigma, Poole, Dorset, UK: dosage given in details of trials below) dissolved in $50 \mathrm{mmol} / \mathrm{l}$ sodium citrate buffer ( $\mathrm{pH} 4.5$ ) immediately before injection. Only those animals whose serum glucose concentration 2 days after injection exceeded $16 \mathrm{mmol} / 1$ were included in the trials.

\section{Trial 1}

This trial was designed to prevent the rise in nerve sorbitol concentrations in diabetic rats by the administration of sorbinil and to correlate this with myo-inositol concentration and MNCV.

MNCV was measured in three groups of age-matched animals. Two groups were injected with streptozotocin $(50 \mathrm{mg} / \mathrm{kg}, \mathrm{IP})$; one group continued as diabetic controls and the second group received sorbinil by gastric intubation once daily $\left(20 \mathrm{mg} \cdot \mathrm{kg}^{-1} \cdot\right.$ day $\left.{ }^{-1}\right)$. Injection of streptozotocin and commencement of sorbinil treatment were performed on the day of the initial MNCV recording. Further MNCV measurements were made at 2,4 and 10 weeks after the induction of diabetes. Sciatic nerve concentrations of sorbitol, fructose, glucose and myo-inositol were determined in groups of rats at 2 weeks and in the remainder at 10 weeks.

\section{Trial 2}

The aim of this trial was to assess the potential of sorbinil or myo-inositol treatment to reverse biochemical changes and slowed MNCV in diabetic rats. MNCV was measured in 80 age-matched rats. Sixty rats were injected with streptozotocin $(35 \mathrm{mg} / \mathrm{kg}$, IP), of which 34 developed diabetes of sufficient severity to be included in the trial. Six weeks later, $\mathrm{MNCV}$ was measured in the control and diabetic groups. The diabetic group was then divided into three sub-groups: one subgroup acted as diabetic controls, another received sorbinil by gastric intubation $\left(25 \mathrm{mg} \cdot \mathrm{kg}^{-1} \cdot \mathrm{day}^{-1}\right)$ and the third sub-group received myo-inositol by gastric intubation $\left(650 \mathrm{mg} \cdot \mathrm{kg}^{-1} \cdot\right.$ day $^{-1} ; 10 \% \mathrm{w} / \mathrm{v}$ in water). The myo-inositol dose was designed to administer an amount equivalent to that ingested from a myo-inositol supplemented diet which has previously been recommended [2]. MNCV was measured 3,6 and 9 weeks following the initiation of treatment. Sciatic nerve sorbitol, fructose, glucose and myo-inositol concentrations were determined 9 weeks after commencement of treatment.

\section{Measurement of $M N C V$}

MNCV was measured by the method of Sharma and Thomas [4]. Rats were anaesthetized with sodium pentobarbitone ('Sagatal', May \& Baker, Dagenham, Essex, UK: $60 \mathrm{mg} / \mathrm{kg}$, IP). Fine needle electrodes were inserted adjacent to the sciatic nerve at the sciatic notch and then at the Achilles tendon. In each case the stimulating electrode was connected across the output of a Grass S88 stimulator (Grass Instruments, Stag Instruments, Henley-on-Thames, UK) with a reference electrode placed subcutaneously in the flank. Electromyograms (EMG) were recorded from the second interosseous muscle of the same limb and displayed on a Tektronix $5103 \mathrm{~N}$ storage oscilloscope (Tektronix UK, Harpenden, Herts, UK). Several EMG were obtained by stimulation (supramaximal voltage; $1 \mathrm{~ms}$ pulses) at the Achilles tendon followed by a second group from stimulation at the sciatic notch. The temporal separation of the two groups of EMG was measured. The length of nerve separating the two stimulation points was measured with dividers and was used to calculate $\mathrm{MNCV}$. This procedure was performed at a constant rectal temperature of $37^{\circ} \mathrm{C}$ with the rats on a heated pad in a room maintained at $25^{\circ} \mathrm{C}$.

\section{Analyses}

For the determination of sugar and sugar alcohol concentrations, sciatic nerves were removed, following MNCV recording, from the level of the sciatic notch and extending approximately $3.5 \mathrm{~cm}$ distally. The epineurium was removed rapidly, the nerve weighed and immediately frozen in liquid nitrogen. Nerves were stored at $-80^{\circ} \mathrm{C}$ until analysis.

To determine fructose, glucose and myo-inostitol concentrations, nerves were placed in boiling distilled water for 3 min followed by homogenisation and deproteinisation with $\mathrm{ZnSO}_{4}$ and $\mathrm{Ba}(\mathrm{OH})_{2}$ as described by Greene et al. [2]. Following centrifugation, aliquots were lyophylised before analysis by gas chromatography as described previously [14] with one modification. The shaking time for the formation of trimethylsilyl derivatives was increased from 4 to $16 \mathrm{~h}$. This method proved to be suitable for the determination of glucose and fructose as well as the heat-stable myo-inositol. Recovery of high concentrations of glucose and fructose added to control rat nerve extractions was 95 and $72 \%$, respectively and this did not alter significantly in extracts which were not boiled. Boiling high concentrations of standard glucose or fructose also did not result in temperature-dependent interconversion of the two sugars.

For the determination of sorbitol concentration, neutralised $\mathrm{HClO}_{4}$ extracts were made as described by Lowry and Passonneau [21]. Following centrifugation, sorbitol was measured by fluorimetric assay using sorbitol dehydrogenase (sheep liver: Sigma) according to the method of Clements et al. [22], in an Aminco-Bowman Spectrophotofluorimeter (American Instruments, Silver Spring, Maryland, USA).

Blood for determination of serum glucose and myo-inositol concentrations was collected from the tail vein. Serum glucose was determined using a glucose test kit (Boehringer, London, UK). Serum myoinositol concentration was measured in $\mathrm{ZnSO}_{4}-\mathrm{Ba}(\mathrm{OH})_{2}$ precipitates as described by Clements and Stockard [17]. Aliquots of the supernatant following centrifugation were lyophylised and subjected to gas chromatography as described previously [14].

For determination of the myo-inositol content of the rat diet, triplicate $500 \mathrm{mg}$ samples of finely powdered diet were extracted three times for $30 \mathrm{~min}$ each time into $10 \mathrm{ml}$ of distilled water in a boiling water bath. Samples were centrifuged between extractions and the supernatants were pooled. The extracts were lyophylised, reconstituted in $5 \mathrm{ml}$ of distilled water and deproteinised by the addition of $\mathrm{ZnSO}_{4}$ $(0.19 \mathrm{~mol} / 1,1 \mathrm{ml})$ and $\mathrm{Ba}(\mathrm{OH})_{2}(0.3 \mathrm{~mol} / 1,1 \mathrm{ml})$. Aliquots of the supernatant following centrifugation were lyophylised with $50 \mu \mathrm{g}$ of methyl- $\alpha$-mannopyranoside as internal standard and subjected to gas chromatography as described previously [14]

\section{Statistical Analysis}

Results are expressed as mean \pm SEM. The significance of difference between the means was calculated using an unpaired Student's t-test with $95 \%$ confidence limits.

\section{Results}

\section{Animals}

Control rats in Trial 1 gained weight throughout the course of the experiment (Table 1). However, the diabet- 
Table 1. Animal weight, serum glucose and myo-inositol concentrations of control and streptozotocin-diabetic rats and the effect of sorbinil or myo-inositol treatment for 10 weeks

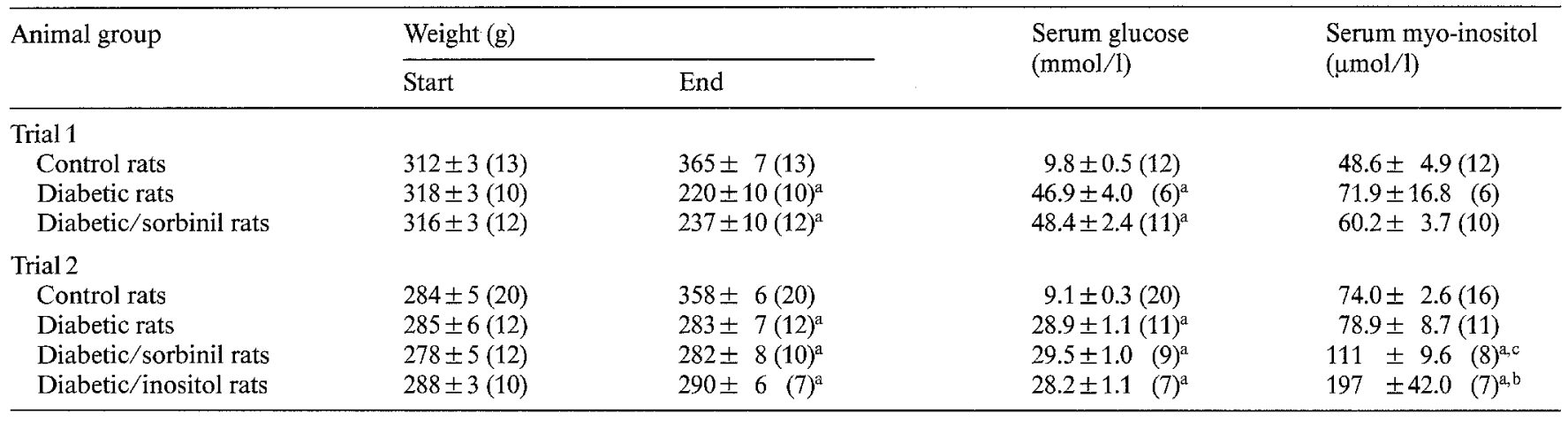

Results are expressed as mean \pm SEM with number of animals in parentheses.

${ }^{a} p<0.001$ versus control; ${ }^{b} p<0.02$ versus diabetic; ${ }^{\mathrm{C}} p<0.01$ versus diabetic

Table 2. Sorbitol, fructose, glucose and myo-inositol concentrations in rat sciatic nerve during streptozotocin diabetes and the effect of sorbinil treatment

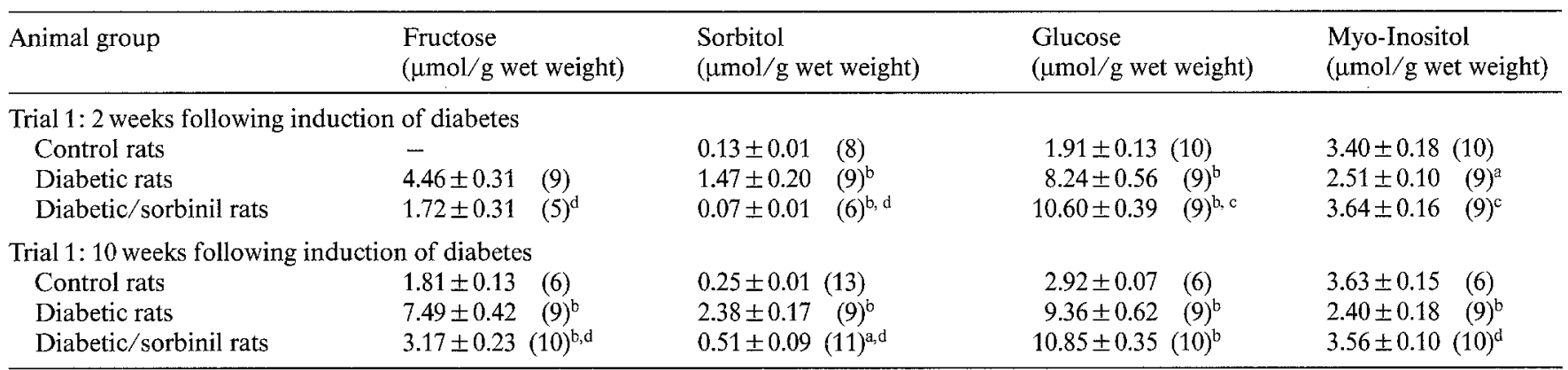

Results are expressed as mean \pm SEM with number of animals in parentheses.

${ }^{a} p<0.01$ versus control; ${ }^{b} p<0.001$ versus control; ${ }^{\mathrm{c}} p<0.01$ versus diabetic; ${ }^{\mathrm{d}} p<0.001$ versus diabetic

ic and sorbinil-treated groups lost weight to $69 \%$ and $75 \%$ of their initial weights, respectively. Serum glucose was markedly and significantly elevated in both the diabetic and sorbinil-treated diabetic groups at the end of the trial. The glucose concentration was higher than anticipated with this dose of streptozotocin and as a result the animals were in extremely poor condition with some deaths during the course of the trial. Serum myo-inositol concentration was elevated in the diabetic and sorbinil-treated groups, although significantly so only in the former.

Due to the severity of diabetes of the animals in Trial 1, the streptozotocin dose was reduced for Trial 2. The elevation of serum glucose at the end of the trial in the diabetic, sorbinil-treated diabetic and myo-inositoltreated diabetic groups was less than that of Trial 1. The diabetic animals in this trial showed no change in body weight by the end of the experiment, while the control group gained weight. At the end of the trial, serum myoinositol concentration was not significantly different between control and diabetic groups, but was significantly elevated compared with controls in both the sorbiniltreated and myo-inositol-treated diabetic groups.

\section{Trial 1: Sciatic Nerve Sugar and Polyol Concentration and Motor Nerve Conduction Velocity}

Sugar and polyol concentrations were measured in sciatic nerves 2 weeks after the start of the trial to confirm changes in these compounds in diabetic rat nerve and to assess the potency of sorbinil treatment. Consistent with previously reported results [2, 14], sorbitol, fructose and glucose concentrations were elevated and myo-inositol concentration decreased in the nerves of the diabetic group after 2 weeks (Table 2). Treatment of diabetic animals with sorbinil for 2 weeks completely prevented the rise in sorbitol concentration and reduced fructose levels, although not to normal. Sorbinil treatment resulted in a significant increase in nerve glucose concentration compared with the diabetic group $(p<$ 0.05 ) and elevated myo-inositol concentration to a level similar to that of control rats.

The rise in nerve sorbitol concentrations after 10 weeks of diabetes was similar to that after 2 weeks (approximately tenfold) although absolute concentrations were higher. However, sorbinil at the dose used in this study and at the extremely high serum glucose con- 
Table 3. Serial motor nerve conduction velocity (MNCV) in rats during streptozotocin diabetes and the effect of sorbinil treatment

\begin{tabular}{|c|c|c|c|c|}
\hline & \multicolumn{4}{|c|}{$\operatorname{MNCV}(\mathrm{m} / \mathrm{s})$} \\
\hline & \multicolumn{4}{|l|}{ Week } \\
\hline & 0 & 2 & 4 & 10 \\
\hline $\begin{array}{l}\text { Control rats } \\
(n=13)\end{array}$ & $38.5 \pm 1.08$ & $40.1 \pm 0.92$ & $39.9 \pm 1.06$ & $42.6 \pm 0.52$ \\
\hline $\begin{array}{l}\text { Diabetic rats } \\
(n=9)\end{array}$ & $40.4 \pm 1.10$ & $39.2 \pm 1.07$ & $38.2 \pm 1.09$ & $34.5 \pm 0.71^{b}$ \\
\hline $\begin{array}{l}\text { Diabetic/ } \\
\text { sorbinil rats } \\
(n=10)\end{array}$ & $40.0 \pm 1.18$ & $38.8 \pm 0.61$ & $36.9 \pm 0.96^{\mathrm{a}}$ & $38.7 \pm 0.73^{b, c}$ \\
\hline
\end{tabular}

Results are expressed as mean \pm SEM. ${ }^{\text {a }} p<0.05$ versus control; ${ }^{\mathrm{b}} p<0.001$ versus control; ${ }^{\mathrm{c}} p<0.001$ versus diabetic rats

Table 4. The effect of short-term sorbinil or myo-inositol treatment on nerve myo-inositol concentration of streptozotocin-diabetic rats

\begin{tabular}{ll}
\hline Animal group & $\begin{array}{l}\text { Myo-Inositol } \\
(\mu \mathrm{mol} / \mathrm{g} \text { wet weight })\end{array}$ \\
\hline Control rats & $3.52 \pm 0.04(5)$ \\
Diabetic rats & $3.03 \pm 0.08(4)^{\mathrm{b}}$ \\
2-day sorbinil/diabetic rats & $3.47 \pm 0.23(3)$ \\
7-day sorbinil/diabetic rats & $3.47 \pm 0.25(3)$ \\
2-day inositol/diabetic rats & $3.37 \pm 0.01(3)^{\mathrm{a}}$ \\
7-day inositol/diabetic rats & $3.78 \pm 0.06(3)^{\mathrm{a}}$ \\
\hline
\end{tabular}

Results are expressed as mean \pm SEM with number of animals in parentheses. Diabetes was of 6 months duration and was induced by a single IP injection of streptozotocin $(35 \mathrm{mg} / \mathrm{kg}$ body weight). a $p<0.02$ versus control; ${ }^{b} p<0.001$ versus control

centrations of these animals did not completely inhibit the enzyme, the reduction in sorbitol concentration being $88 \%$. Fructose concentration was significantly higher than in control rats. Consistent with results obtained at 2 weeks, sorbinil treatment prevented a fall in myoinositol concentration which had decreased by approximately $30 \%$ in the untreated diabetic rats after 10 weeks of diabetes.

During the 10 -week trial, $\mathrm{MNCV}$ of the control group increased significantly $(p<0.01$; Table 3$)$. In contrast, MNCV of the untreated diabetic group decreased gradually throughout the trial, although a statistically significant decrease was attained only by week 10 . Sorbinil treatment of diabetic rats did not prevent a decrease in MNCV and the difference compared with controls was significant at week 10 . However, there was an improvement in MNCV of the sorbinil-treated group between weeks 4 and 10 (NS) and MNCV at week 10 was significantly higher than that of the untreated diabetic animals.

\section{Trial 2: Sciatic Nerve Sugar and Polyol Concentrations and Motor Nerve Conduction Velocity}

In view of the finding that sorbinil treatment of diabetic rats restores sciatic nerve myo-inositol concentration to normal (Table 1), Trial 2 included a myo-inositol-treated diabetic group as a comparison to sorbinil treatment. Detailed nerve sugar and polyol results were presented as Table 2 in the preliminary report [20] and are not repeated here.

Reduction of the streptozotocin dose resulted in lower serum glucose concentrations in the diabetic rats (Table 1). Sciatic nerve glucose concentration was reduced compared with that of Trial 1 ( 10 week measurement), although it was significantly higher than that of control rats. Nerve fructose and sorbitol concentrations in the untreated diabetic group were significantly elevated, the extent of the increase of the latter being unaccountably more than that seen in Trial 1 where ambient glucose concentrations were higher (Tables 1 and 2). However, the increased sorbinil dose administered to the diabetics was sufficient to restore both increased sorbitol and decreased myo-inositol concentrations to control values. Indeed restoration of normal sorbitol concentrations in 2 week diabetic rats $(75 \mathrm{mg} / \mathrm{kg}$ streptozotocin) was achieved after only 3 days of sorbinil treatment $\left(20 \mathrm{mg} \cdot \mathrm{kg}^{-1} \cdot \mathrm{day}^{-1}\right)$ (control rats: not measurable (by gas chromatography), diabetic rats: $1.15 \mu \mathrm{mol} / \mathrm{g}$, sorbinil-treated diabetic rats: not measurable) and 2 days of this treatment of 6 month diabetic rats $(35 \mathrm{mg} / \mathrm{kg}$ streptozotocin) returned myo-inositol concentration to levels not significantly different from control values (Table 4).

Myo-Inositol treatment raised serum myo-inositol concentrations almost threefold (Table 1); this resulted in a normalisation of sciatic nerve myo-inositol concentration which was achieved in 6-month diabetic rats after 7 days of treatment (Table 5). This treatment regimen had no effect on sorbitol, fructose or glucose concentrations in sciatic nerve.

Initial MNCVs of the control rats and those which subsequently became diabetic were similar (Table 5). These results were re-calculated from the experiments of Table 1 of the preliminary account [20], omitting values from rats which died later in the trial. Six weeks following the induction of diabetes, MNCV of both groups had increased, although that of the diabetic group was elevated to a significantly smaller extent (control versus total diabetic group, $p<0.001$ ). At this point the diabetic group was divided into three subgroups with similar MNCV's which were significantly different from controls as described in the Methods section. MNCV of the control and diabetic groups did not alter significantly during the 9-week treatment period. At all times during the treatment period MNCV of the untreated diabetics was significantly slowed compared with that of control rats. Sorbinil treatment of diabetics for 3 weeks did not alter MNCV (Table 5). However, continuing treatment with sorbinil induced a gradual improvement in MNCV which was not significantly different from controls at the end of the treatment period. In contrast with sorbinil treatment, administration of myo-inositol for 3 weeks returned MNCV to normal 
Table 5. Serial motor nerve conduction velocity (MNCV) in rats during streptozotocin diabetes and the effect of myo-inositol or sorbinil treatment in Trial 2: treatment with sorbinil or inositol began at Week 6

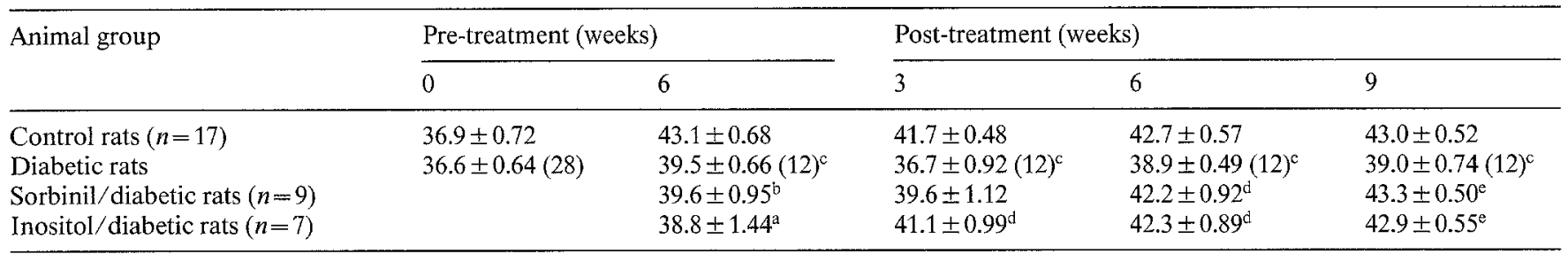

Results are expressed as mean \pm SEM with number of animals in parentheses.

${ }^{\mathrm{a}} p<0.02$ versus control; ${ }^{\mathrm{b}} p<0.01$ versus control; ${ }^{\mathrm{c}} p<0.001$ versus control; ${ }^{\mathrm{d}} p<0.01$ versus diabetic; ${ }^{\mathrm{e}} p<0.001$ versus diabetic

and this improvement was maintained until the end of treatment (Table 5). MNCV of the sorbinil-treated diabetic group was significantly higher than that of the untreated diabetic group after 6 and 9 weeks of treatment while MNCV of the myo-inositol-treated diabetic group was higher throughout the treatment period.

\section{Discussion}

Sorbinil proved to be a potent inhibitor of aldose reductase in vivo since it completely prevented a rise in sciatic nerve sorbitol concentration during the early stages of experimental diabetes. This prevention was not maintained during the 10-week experimental period, but this may have been due to an insufficiently high dose of sorbinil or to the extremely high serum glucose concentrations in these animals. However, despite persistent hyperglycaemia and elevated nerve glucose concentrations, sorbinil treatment resulted in an $88 \%$ inhibition of the increase in sorbitol concentration and a reduction in fructose levels. Not only could sorbinil treatment prevent or reduce the extent of elevation in nerve sorbitol concentrations, it was found also to reduce efficiently already elevated sorbitol concentrations. This reduction appeared to be complete only 3 days after initiation of treatment. Reversal of increased sorbitol concentrations also resulted in a near-normalisation of nerve fructose levels.

Sorbinil treatment consistently increased nerve glucose concentration although this was significantly different on only one occasion compared with untreated diabetic rats. This increase may simply be caused by the inhibition of glucose entry into the polyol pathway. It is not known if this exacerbation of already high glucose concentrations results in further biochemical alterations.

Prevention of the elevation in sorbitol concentrations during experimental diabetes also prevented loss of free myo-inositol from peripheral nerve and this effect was maintained until the end of the trial despite a small significant rise in sorbitol concentrations. Reversing already elevated sorbitol concentrations with sorbinil treatment also resulted in a near normalisation of myo-inositol concentration which was reduced by $30 \%$ in untreated animals at the end of the trial. Treatment of diabetic rats with sorbinil for only 2 days was sufficient to increase nerve myo-inositol concentration to levels similar to controls, which suggests that the accumulation of sugar alcohols in peripheral nerve during experimental diabetes may be responsible for the loss of myoinositol. Experiments in vitro suggest that this may be through an effect on the active transport of inositol [23], a process which has been described independently by Greene and Lattimer [24].

Modification of the transport mechanism for myoinositol in peripheral nerve in vivo is evident since elevation of serum myo-inositol concentration by dietary myo-inositol results in near-normalisation of nerve myo-inositol levels. The latter has been demonstrated previously using inositol-supplemented diets $[2,25,26]$. The control serum inositol concentration of Trial 1 was unexpectedly low in comparison with our earlier finding of $80 \mu \mathrm{mol} / 1$ [14]. Trial 2 gave a control figure of $74 \mu \mathrm{mol} / \mathrm{l}$. These concentrations are higher than those of Greene et al. [2], possibly because our rat diet had $0.022 \%$ inositol by weight, while theirs had only $0.011 \%$ inositol. In our hands, tail-vein and cardiac blood samples gave similar concentrations of inositol. In the present study, elevation of nerve myo-inositol concentration in myo-inositol-treated diabetic rats was observed after 2 days of treatment and 7 days of treatment results in complete normalisation. In both trials described here, serum myo-inositol also was elevated during sorbinil treatment. The possibility therefore exists that sorbinil treatment increased nerve myo-inositol concentration and conduction velocity through increased serum myoinositol concentration with resultant increased transport. However, our study in vitro [23] suggests that sorbinil partly reverses glucose-inhibited myo-inositol transport with no elevation in medium myo-inositol concentration.

Although peripheral nerve sorbitol and myo-inositol were maintained near-normal throughout a 10 -week period, sorbinil treatment was unable to prevent gradual slowing of MNCV in diabetic rats although a slight improvement was evident late in the trial. It was not possible to investigate this further, since the animals were in extremely poor condition and the trial was therefore terminated. However, it was found that both 
sorbinil and myo-inositol treatment could reverse slowed MNCV in diabetic rats over 9 weeks of treatment. Since this reversal was possible in the myo-inositol-treated group without reduction of nerve sorbitol and since myo-inositol was normalised in both cases, it appears that elevated nerve sorbitol is unconnected with the slowing in MNCV, but may lead to this through its effect on myo-inositol metabolism.

A return to normal of nerve sorbitol concentration and $\mathrm{MNCV}$ in diabetic rats following sorbinil treatment [27] or prevention of slowing of MNCV with ICI 105552 treatment [28] have been reported recently and this study confirms these former results. However, some controversy exists concerning the effect of myo-inositol $[2,5,25,26]$. We have achieved normal values of MNCV by different treatments which both restore nerve myoinositol concentrations; this further strenghthens the argument for the involvement of myo-inositol and the polyphosphoinositides in peripheral nerve function.

Extrapolation of these results to treatment of human diabetic neuropathy should be made with caution. Results with either of the two treatments have not proved entirely encouraging. Clinical trials with myo-inositol treatment have shown results ranging from no effect [29], to improvement in some electrophysiological parameters [30,31]. Human trials using various aldose reductase inhibitors also have proved inconsistent, with effects varying from no change in conduction velocities to improvement in both sensory and motor conduction [32-35]. However, analysis of post-mortem material [36, 37] and human nerve biopsies [38] suggests that alterations of polyol pathway activity and myo-inositol metabolism occur in nerves from human diabetics and encourages further experiments with these treatments.

Acknowledgements. KRWG was in receipt of a post-doctoral research fellowship from the British Diabetic Association. We thank Pfizer Ltd., Sandwich, Kent, UK, for financial support and supplies of sorbinil, Miss B. Filipowicz for technical assistance and Mrs. J.Paxton for manuscript preparation.

\section{References}

1. Eliasson SG (1964) Nerve conduction changes in experimental diabetes. J Clin Invest 43: 2353-2358

2. Greene DA, De Jesus PV, Winegrad AI (1975) Effects of insulin and dietary myo-inositol on impaired peripheral motor nerve conduction velocity in acute streptozotocin diabetes. J Clin Invest 55: 1326-1336

3. Hildebrand J, Joffroy A, Graff G, Coers C (1968) Neuromuscular changes with alloxan hyperglycemia. Arch Neurol 18: 633-641

4. Sharma AK, Thomas PK (1974) Peripheral nerve structure and function in experimental diabetes. J Neurol Sci 23: 1-15

5. Thomas PK, Jefferys JGR, Sharma AK, Bajada S (1981) Nerve conduction velocity in experimental diabetes in the rat and rabbit. J Neurol Neurosurg Psychiatr 44: 233-238

6. Jakobsen J (1979) Early and preventable changes of peripheral nerve structure and function in insulin-deficient diabetic rats. J Neurol Neurosurg Psychiatr 42: 509-518

7. Moore SA, Peterson RG, Felten DL, O'Connor BL (1980) A quantitative comparison of motor and sensory conduction veloci- ties in short- and long-term streptozotocin- and alloxan-diabetic rats. J Neurol Sci 48: 133-152

8. Bell ME, Peterson RG, Eichberg J (1982) Metabolism of phospholipids in peripheral nerve from rats with chronic streptozotocin-induced diabetes: increased turnover of phosphatidylinositol-4,5bisphosphate. J Neurochem 39: 192-200

9. Brown MJ, Sumner AJ, Greene DA, Diamond SM, Asbury AK (1980) Distal neuropathy in experimental diabetes mellitus. Ann Neurol 8: 168-178

10. Sharma AK, Bajada S, Thomas PK (1981) Influence of streptozotocin-induced diabetes on myelinated nerve fibre maturation and on body growth in the rat. Acta Neuropathol (Berl) 53:257-265

11. Yagihashi S, Kudo K, Nishihira M (1979) Peripheral nerve structures of experimental diabetes rats and the effect of insulin treatment. Tohoku J Exp Med 127: 35-44

12. Zemp C, Bestetti G, Rossi GL (1981) Morphological and morphometric study of peripheral nerves from rats with streptozotocininduced diabetes mellitus. Acta Neuropathol (Berl) 53: 99-106

13. Clements RS (1979) Diabetic neuropathy - new concepts of its etiology. Diabetes 28: 604-611

14. Palmano KP, Whiting PH, Hawthorne JN (1977) Free and lipid myo-inositol in tissues from rats with acute and less severe streptozotocin-induced diabetes. Biochem J 167: 229-235

15. Gabbay KH (1973) The sorbitol pathway and the complications of diabetes. N Engl J Med 288: 831-836

16. Whiting PH, Palmano KP, Hawthorne IN (1979) Enzymes of myo-inositol and inositol lipid metabolism in rats with streptozotocin-induced diabetes. Biochem J 179: 549-553

17. Clements RS, Stockard CR (1980) Abnormal sciatic nerve myoinositol metabolism in the streptozotocin-diabetic rat. Diabetes 29: $227-235$

18. Natarajan V, Dyck PJ, Schmid HHO (1981) Alterations of inositol lipid metabolism of rat sciatic nerve in streptozotocin-induced diabetes. J Neurochem 36: 413-419

19. White GL, Schellhase HU, Hawthorne JN (1974) Phosphoinositide metabolism in rat superior cervical ganglion, vagus and phrenic nerve: effects of electrical stimulation and various blocking agents. J Neurochem 22: 149-158

20. Gillon KRW, Hawthorne JN (1983) Sorbitol, inositol and nerve conduction in diabetes. Life Sci 32: 1943-1947

21. Lowry OH, Passonneau JV (1972) Preparation of tissues for analysis. In: A flexible system of enzymatic analysis. Academic Press, New York, pp 120-126

22. Clements RS, Morrison AD, Winegrad AI (1969) Polyol pathway in aorta: regulation by hormones. Science 166: 1007-1008

23. Gillon KRW, Hawthorne JN (1983) Transport of myo-inositol into endoneurial preparations of sciatic nerve from normal and streptozotocin-diabetic rats. Biochem J 210: 775-781

24. Greene DA, Lattimer SA (1982) Sodium- and energy-dependent uptake of myo-inositol by rabbit peripheral nerve. J Clin Invest 70: 1009-1018

25. Jefferys JGR, Palmano KP, Sharma AK, Thomas PK (1978) Influence of dietary myo-inositol on nerve conduction and inositol phospholipids in normal and diabetic rats. J Neurol Neurosurg Psychiatr 41: 333-339

26. Greene DA, Lewis RA, Lattimer SA, Brown MJ (1982) Selective effects of myo-inositol administration on sciatic and tibial motor nerve conduction parameters in the streptozotocin-diabetic rat. Diabetes 31: 573-578

27. Yue DK, Hanwell MA, Satchell PM, Turtle JR (1982) The effect of aldose reductase inhibition on motor nerve conduction velocity in diabetic rats. Diabetes 31: 789-794

28. Tomlinson DR, Holmes PR, Mayer JH (1982) Reversal, by treatment with an aldose reductase inhibitor, of impaired axonal transport and motor nerve conduction velocity in experimental diabetes mellitus. Neurosci Lett 31: 189-193

29. Gregersen G, Borsting H, Theil P, Servo C (1978) Myo-inositol and function of peripheral nerves in human diabetics. Acta Neurol Scandinav 58: 241-248

30. Clements RS, Vourganti B, Kuba T, Oh SJ, Darnell B (1979) Di- 
etary myo-inositol intake and peripheral nerve function in diabetic neuropathy. Metabolism 28 (Suppl 1): 477-483

31. Salway JG, Whitehead L, Finnegan JA, Karunanayaka A, Barnett D, Payne RB (1978) Effect of myo-inositol on peripheral nerve function in diabetes. Lancet 2: 1282-1284

32. Gabbay KH, Spack N, Loo S, Hirsch HJ, Ackil AA (1979) Aldose reductase inhibition: studies with alrestatin. Metabolism 28 (Suppl 1): $471-476$

33. Fagius J, Jameson S (1981) Effects of aldose reductase inhibitor treatment in diabetic polyneuropathy - a clinical and neurophysiological study. J Neurol Neurosurg Psychiatr 44: 991-1001

34. Culebras A, Alio J, Herrera J-L, Lopez-Fraile MIP (1981) Effect of an aldose reductase inhibitor on diabetic peripheral neuropathy. Arch Neurol 38: 133-134

35. Judzewitsch RG, Jaspan JB, Polonsky KS, Weinberg CR, Halter JB, Halar E, Pfeifer MA, Vukadinovic C, Bernstein L, Schneider M, Liang K-Y, Gabbay KH, Rubenstein AH, Porte D (1983) Aldose reductase inhibition improves nerve conduction velocity in diabetic patients. $\mathrm{N}$ Engl J Med 308: 119-125

36. Mayhew JA, Gillon KRW, Hawthorne JN (1983) Free and lipid inositol, sorbitol and sugars in sciatic nerve obtained post-mortem from diabetic patients and control subjects. Diabetologia 24: 13-15

37. Ward JD (1973) The polyol pathway in the neuropathy of early diabetes. In: Camaerini-Davalos RA, Cole HS (eds) Vascular and neurological changes in early diabetes. Advances in metabolic disorders, Suppl 2. Academic Press, New York, pp 425-429

38. Dyck PJ, Sherman WR, Hallcher LM, Service FJ, O'Brien PC, Grina LA, Palumbo PJ, Swanson CJ (1980) Human diabetic endoneurial sorbitol, fructose and myo-inositol related to sural nerve morphometry. Ann Neurol 8: 590-596

Accepted: 21 December 1982

and in revised form: 5 July 1983

Dr. K.R.W. Gillon

Professor J. N. Hawthorne

Department of Biochemistry

University Hospital and Medical School

Queen's Medical Centre

Nottingham NG7 2UH, UK 